\title{
Strength training in elderly people improves static balance: a randomized controlled trial
}

\author{
Sarabon Nejc (1,2), Stefan Loefler (1), Jan Cvecka (3), Milan Sedliak (3), Helmut \\ Kern $(1,4)$
}

(1) Ludwig Boltzmann Institute of Electrical Stimulation and Physical Rehabilitation, Vienna, Austria; (2) University of Primorska, Science and Research Centre, Koper, Slovenia; (3) Faculty of Physical Education and Sport, Comenius University, Bratislava, Slovakia; (4) Institute of Physical Medicine and Rehabilitation, Wilhelminenspital, Austria, Vienna

\begin{abstract}
Aim of this study was to investigate the effects of two different types of strength training programs on static balance in elderly subjects. Subjects older than 65 years of age were enrolled and assigned to control group $(\mathrm{CG}, \mathrm{n}=19)$, electrical stimulation group (ES, $n=27$ ) or leg press group ( $\mathrm{LP}, \mathrm{n}=28$ ). Subjects in both the training groups were exposed to training (2-3x/week) for a period of 9 weeks. In the ES group the subjects received neuromuscular electrical stimulation of the anterior thigh muscles. In the LP group the subjects performed strength training on a computer-controlled leg press machine. Before and after the training period, static balance of the subject was tested using a quiet stance task. Average velocity, amplitude and frequency of the center-of-pressure (CoP) were calculated from the acquired force plate signal. The data was statistically tested with analysis of (co)variance and t-tests. The three groups of subjects showed statistically significant differences $(p<0.05)$ regarding the pre-training vs. post-training changes in CoP velocity, amplitude and frequency. The differences were more pronounced for CoP velocity and amplitude, while they were less evident in case of mean frequency. The mean improvements were higher in the LP group than in the ES group. Our results provide supportive evidence to the existence of the strengthbalance relationship. Additionally, results indicate the role of recruiting central processes and activation of functional kinetic chains for the better end effect.
\end{abstract}

Key Words: aging, falls, balance, strength, training

European Journal Translational Myology - Basic Applied Myology 2013; 23 (3): 85-89

Falls and their consequences are a major health problem in elderly population [26]. Poor balance has been recognized as one of many precursors of falls [9,21]. Sustaining postural equilibrium during an upright stance and during locomotion is, by itself, a major concern for the human neuromuscular system. Moreover, secondary functional goals, such as performance of powerful or precise movements, can be compromised in case balance has been lost. Poor balance can affect even daily tasks such as standing, reaching for objects, rising from a bed, and other [7]. Balance therefore represents an important pillar for the quality of body motion and for the quality of life. On one hand, impaired balance can be a result of several reasons such as injury [20], disease [5, 15] or aging [30]. On the other hand, growing body of literature shows that balance can be improved through sensorymotor (i.e. proprioceptive) training $[7,13]$.

The population of elderly people is probably among the most sensitive groups of people regarding the decline of postural stability and general mobility. This comes as a combined effect of a less active lifestyle and of biological processes. The latter encompass also loss of muscle mass (i.e. sarcopenia) [28] and decreased ability for voluntary neuromuscular activation [16] which in turn result in the drop of muscle strength and power [14, 23]. The relationship between balance and strength has been identified, although the reports on that are somehow contrasting and the cause-effect relationship cannot be simply defined. Therefore, the aim of this study was to find out the effects of nine-week strength training on static balance in elderly subjects. Additionally, two types of 
Table 1. Training plan for the LP group

\begin{tabular}{lccccccccc} 
Week & $\mathbf{1}^{\text {st }}$ & $\mathbf{2}^{\text {nd }}$ & $\mathbf{3}^{\text {rd }}$ & $\mathbf{4}^{\text {th }}$ & $\mathbf{5}^{\text {th }}$ & $\mathbf{6}^{\text {th }}$ & $\mathbf{7}^{\text {th }}$ & $\mathbf{8}^{\text {th }}$ & $\mathbf{9}^{\text {th }}$ \\
\hline \hline Sessions/week & 2 & 2 & 3 & 3 & 3 & 3 & 3 & 3 & 3 \\
Sets/session & 4 & 4 & 4 & 4 & 5 & 5 & 5 & 5 & 5 \\
Time/set [s] & $8-10$ & $8-10$ & $8-10$ & $8-10$ & $8-10$ & $10-12$ & $10-12$ & $12-14$ & $12-14$ \\
Inter-set break [s] & 120 & 120 & 120 & 120 & 120 & 120 & 120 & 120 & 120
\end{tabular}

training (electrical stimulation vs. voluntary exercise) were used and specific effects were searched for.

\section{Materials and Methods}

\subsection{Subjects}

Altogether, 87 subjects volunteered to take part and 74 subjects $(74.3 \pm 7.0$ years, $169.6 \pm 10.3 \mathrm{~cm}, 78.5 \pm$ $16.1 \mathrm{~kg}$ ) completed it. 13 subjects did not complete the training from personal reasons not related to the study. They were randomly assigned to control group (CG, $\mathrm{n}$ $=19)$, electrical stimulation group (ES, $n=27$ ) or leg press group ( $\mathrm{LP}, \mathrm{n}=28$ ). Study design, measurement procedures, benefits and potential risks were explained to the subjects prior to their enrolment. The study protocol was approved by the national medical ethics committee (Ethic committee of the city of Vienna nr. 08-102-0608) and subjects gave their written informed consent before the inclusion.

\section{Study Design}

A randomized controlled study design was used. Subjects in both training groups (ES and LP) were exposed to training for a period of nine weeks, while the subjects assigned to the CG continued with their normal life not being exposed to any systematic physical conditioning programme. Before and after the training period, the subjects underwent a set of clinical and laboratory tests, among other, also the assessment of static balance.

\section{Measurements}

On each of the two occasions (pre-training and posttraining) the subject performed so called quiet stance task, with feet positioned parallel at hip width and vision restricted using a non-transparent mask. An introductory trial was performed and followed by tree 30 -s repetitions; divided by 60 -s rest intervals. The subject was standing on a force platform (Fitro Sway, Bratislava, Slovakia) while performing the balance task and the centre-of-pressure $(\mathrm{CoP})$ signal was acquired at $100 \mathrm{~Hz}$ and stored on the PC for further analysis. The signal was pre-processed (low-pass $10 \mathrm{~Hz}$ Butterworth filter, second-order) and then quantified with average velocity, amplitude and frequency of $\mathrm{CoP}$ (total, medial-lateral and anterior-posterior direction) .

\section{Training}

Subjects in both the training groups (ES and LP) were exposed to regular training for a period of nine weeks. In the ES group the subjects received neuromuscular electrical stimulation of the anterior thigh muscles. In the LP group the subjects performed strength training on a computer-controlled leg press machine using the mode of combined slow movements and superponated vibrations.

ES training was performed with a custom-built batterypowered stimulator [12]. The subject was seated over the edge of the therapeutic table with the trunk upright and lower legs freely swinging. Two conductive rubber electrodes $(9 \times 14 \mathrm{~cm})$ cowered by wet sponge were placed on the anterior thigh on each side of the body. The electrode pairs were connected to the independent channels of the stimulator and the left and the right thigh were stimulated in an alternative manner. Each repetition (i.e. ES evoked muscle contraction) was evoked by a $3.5 \mathrm{~s}$ train $(60 \mathrm{~Hz})$ of electrical pulses (rectangular, biphasic, width $0.6 \mathrm{~ms}$ ). Consecutive contractions of the same thigh were separated by $4.5 \mathrm{~s}$ off intervals. During the first two weeks of the training period, two sessions per week were carried out and each session consisted of 45 contractions ( 3 sets $\times 15$ repetitions) on each thigh. This was progressed during weeks 3 to 9 so that the total training volume per week came to 2.5-times of the initial (3 sessions/week, 75 contractions/thigh/session). Maximal tolerable intensity was used and monitored during the training sessions. In all the subjects in the ES group this induced a tetanic contraction of the stimulated muscles. Subjects in the LP group trained on a custom built, computer controlled, linear electric motor powered leg press device [10]. The so called "swinging" vibrational-proprioceptive mode was used, which means that constant velocity of the pedals $(0.3 \mathrm{~m} / \mathrm{s}$ and $0.2 \mathrm{~m} / \mathrm{s}$ for concentric and eccentric phase, respectively) was interrupted by short stops (every 8 $\mathrm{mm}$ ), resulting in short force peaks appearing throughout the movement. Training load was progressively increased throughout the nine-week period as presented in Table 1. 


\section{Elderly - Strength for Balance}

European Journal Translational Myology - Basic Applied Myology 2013; 23 (3): 85-89

\section{Statistical Analysis}

Statistical analysis was done using PASW Statistics 18 software (SPSS Inc., Quarry Bay, Hong Kong). Descriptive statistics, tests of normality and homoscedasticity were performed first. This was followed by testing the differences among the three groups (CG, ES, and LP) in the context of time (preintervention vs. post-intervention) using analysis of (co)variance and 2-tailed t-tests with Bonferroni corrections. Values are reported as mean (standard error). The level of statistical significance was set at 0.05 .

\section{Results and Discussion}

As mentioned before, drop out of subjects from the study was $\sim 15 \%$. Additionally, four obvious outliers (> 3 SD from mean) were excluded from statistical analyses. Such a dataset was used for statistical comparisons. All the dependent variables were normally distributed. The three groups of subjects (CG, ES, and LP) showed statistically significant differences $(\mathrm{p}<0.05)$ regarding the pre-training vs. post-training changes in CoP velocity, amplitude and frequency (Table 2). The differences were more pronounced for CoP velocity $(\mathrm{F}=4.9-9.6, \mathrm{p}=0.000-0.001)$ and amplitude $(\mathrm{F}=5.6-8.5, \mathrm{p}=0.001-0.006)$, while they were less evident in case of mean frequency of the power spectrum $(F=1.6-3.6, p=0.03-0.21)$. The mean improvements were higher in the LP group than in the ES group.

Results of this randomized controlled trial showed statistically significant effect of a nine-week strength training in elderly subjects on the body sway parameters during symmetrical bipedal stance with closed eyes. Specifically, the training effect was more evident in the subjects who performed voluntary activation of lower extremities' muscles (LP group) and less evident in subjects who received training with artificially evoked contractions of the anterior thigh muscles only (ES group).

Biological processes of neuromuscular aging lead to a decrease in physical and mental functions, which is more evident in people with a passive lifestyle [4, 6]. Impairments have been shown for cardio respiratory endurance, inter-joint and inter-muscle coordination, precision of movement, flexibility, balance, and strength $[2,8]$. These aging related changes have some common origins encompassing sarcopenia, muscle fibre type transformation, loss of sensory functions, reduction in the number of neurons, and neuroplasticity changes $[1,11,24]$. The latter has also been shown to be a reason for cognitive functions decay taking place through the aging process [25, 27]. However, several studies have shown that these negative trends can be effectively compensated using movement interventions of different kinds [7, 13]. Results of our study support such conclusions and advance knowledge about training specific effects in the context of balance.

Strength and balance (i.e. mechanical stability) represent ground stones for daily functional movements. Sustaining balance of an inherently unstable system such as human body is characterized by continuous automatic (reflexive and anticipatory) fine sensory-motor tuning of lower extremity muscles [29]. To the contrary, isometric muscle strength is defined as the ability to generate maximal force/torque,

Table 2: Results - training effects and differences among groups

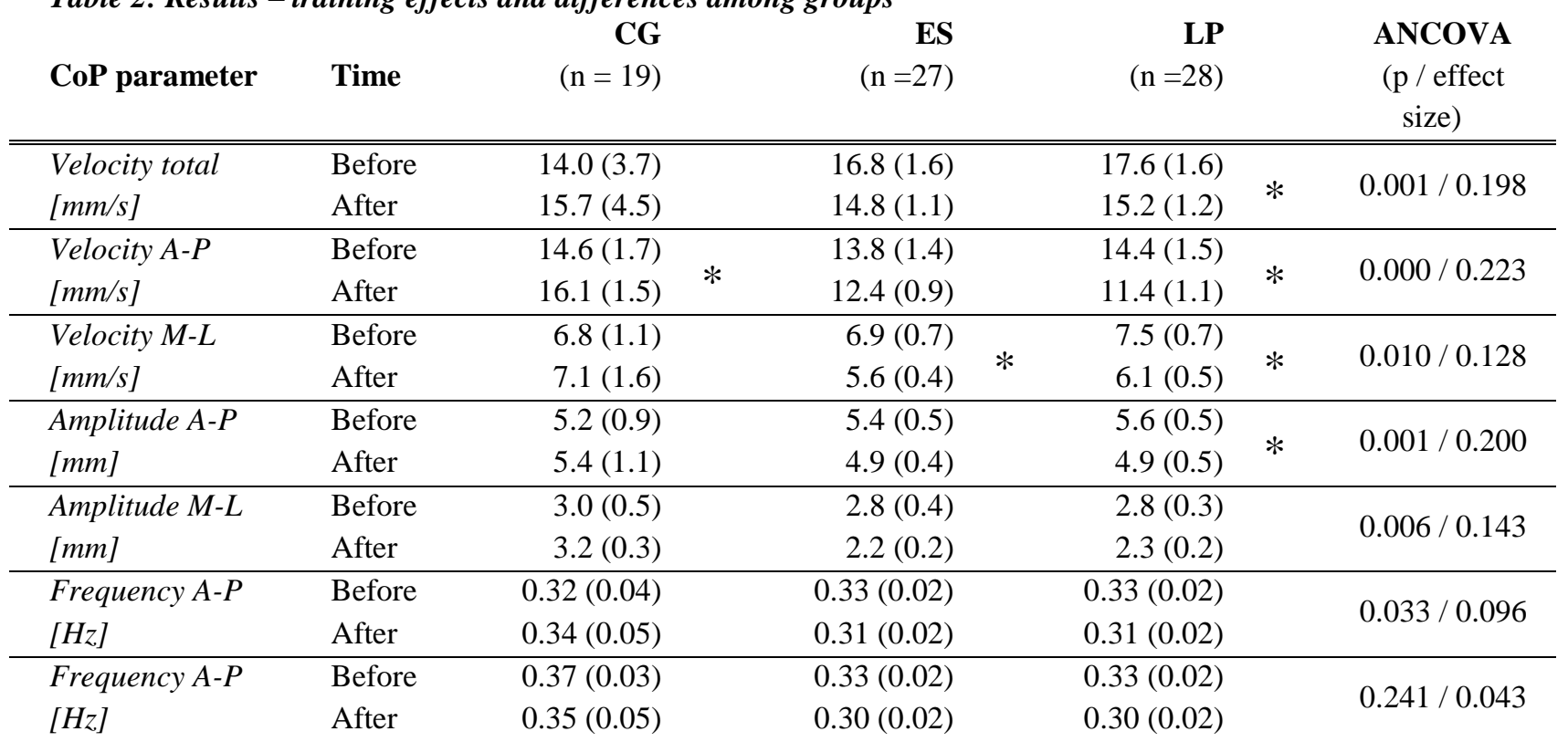

Note: asterisks represent statistically significant before-after differences (pairwise t-test, $p<0.05$ ). 


\section{Elderly - Strength for Balance}

European Journal Translational Myology - Basic Applied Myology 2013; 23 (3): 85-89

the role of sensory information is less and it primarily relies on voluntary action. If only strength and balance are somehow different in their underlying mechanisms, several studies have shown that they do correlate at a small to medium level [3,21,22]. On the contrary, other studies have shown absence of correlation between strength and balance proposing the role of complementary diagnostics and training in their regard [17-19].

Our results are supportive to the above presented strength-balance relationship. Namely both experimental groups of subjects (LP and ES) showed improvements in the indexes of balance. These changes were more pronounced in subjects who performed maximal voluntary actions under proprioception facilitating conditions (i.e. dynamic movement with interpolated low-frequency vibrations). Subjects who trained with neuromuscular electrical stimulation showed lower improvements in static balance, potentially because of the specific characteristics of such training among which are (i) isolated training of knee extensors, (ii) submaximal activation of muscles, (iii) inverted order of motor units recruitment, (iv) absence of voluntary action and (v) less sensory-motor integration involved.

To summarize, our results provide supportive evidence to the existence of the strength:balance relationship. Some of the selected body sway parameters were namely improved after the training period in both experimental groups. The training effect on static balance was bigger in case of training with voluntary contractions and less when neuromuscular electrical stimulation was used. This might indicate the role of recruiting central (supraspinal and spinal) processes and activation of functional kinetic chains for the better end effect

\section{Acknowledgements}

The authors would like to acknowledge the support of: (1) the European Regional Development Fund for funding the Cross Border Cooperation Programme Slovakia - Austria 2007 - 2013 (Interreg-IVa), project Mobilität im Alter, MOBIL, N_00033 (partners: Ludwig Boltzmann Institute of Electrical Stimulation and Physical Rehabilitation, Austria, Center for Medical Physics and Biomedical Engineering, Medical University of Vienna, Austria and Faculty of Physical Education and Sports, Comenius University in Bratislava, Slovakia) and (2) the Austrian national cofinancing of the Austrian Federal Ministry of Science and Research.

\section{Corresponding Author}

Nejc Sarabon, PhD. University of Primorska, Science and Research Center, Institute for Kinesiology Research. Garibaldijeva 1 SI-6000 Koper, Slovenia e-mail: nejc.sarabon@zrs.upr.si

\section{References}

[1] Berger MJ, Doherty TJ. Sarcopenia: prevalence, mechanisms, and functional consequences. Interdisciplinary topics in gerontology 2010;37:94-114.

[2] Blankevoort CG, van Heuvelen MJ, Boersma F, Luning $\mathrm{H}$, de Jong J, Scherder EJ. Review of effects of physical activity on strength, balance, mobility and ADL performance in elderly subjects with dementia. Dementia and geriatric cognitive disorders 2010;30:392-402.

[3] Brech GC, Alonso AC, Luna NM, Greve JM. Correlation of postural balance and knee muscle strength in the sit-to-stand test among women with and without postmenopausal osteoporosis. Osteoporosis international 2013

[4] Bula CJ, Monod S, Hoskovec C, Rochat S. Interventions aiming at balance confidence improvement in older adults: an updated review. Gerontology 2011;57:276-86.

[5] Cameron MH, Lord S. Postural control in multiple sclerosis: implications for fall prevention. Curr Neurol Neurosci Rep 2010;10:407-12.

[6] Chodzko-Zajko WJ, Moore KA. Physical fitness and cognitive functioning in aging. Exerc Sport Sci Rev 1994;22:195-220.

[7] Chou CH, Hwang CL, Wu YT. Effect of exercise on physical function, daily living activities, and quality of life in the frail older adults: a metaanalysis. Arch Phys Med Rehabil 2012;93:23744.

[8] den Ouden ME, Schuurmans MJ, Arts IE, van der Schouw YT. Physical performance characteristics related to disability in older persons: a systematic review. Maturitas 2011;69:208-19.

[9] Granata KP, Lockhart TE. Dynamic stability differences in fall-prone and healthy adults. $\mathbf{J}$ Electromyogr Kinesiol 2008;18:172-8.

[10] Kern H, Pelosi L, Coletto L, Musaro A, Sandri M, Vogelauer M, et al. Atrophy/hypertrophy cell signaling in muscles of young athletes trained with vibrational-proprioceptive stimulation. Neurol Res 2011;33:998-1009.

[11] Kraft E. Cognitive function, physical activity, and aging: possible biological links and implications for multimodal interventions. Neuropsychology, development, and cognition Section B, Aging, neuropsychology and cognition 2012;19:248-63.

[12] Krenn M, Haller M, Bijak M, Unger E, Hofer C, Kern $\mathrm{H}$, et al. Safe neuromuscular electrical stimulator designed for the elderly. Artif Organs 2011;35:253-6.

[13] Lord SR, Ward JA, Williams P. Exercise effect on dynamic stability in older women: a randomized controlled trial. Arch Phys Med Rehabil 1996;77:232-6. 


\section{Elderly - Strength for Balance}

European Journal Translational Myology - Basic Applied Myology 2013; 23 (3): 85-89

[14] Macaluso A, De Vito G. Muscle strength, power and adaptations to resistance training in older people. Eur J Appl Physiol 2004;91:450-72.

[15] Mirelman A, Herman T, Nicolai S, Zijlstra A, Zijlstra W, Becker C, et al. Audio-Biofeedback training for posture and balance in Patients with Parkinson's disease. J Neuroeng Rehabil 2011;8.

[16] Morse CI, Thom JM, Davis MG, Fox KR, Birch KM, Narici MV. Reduced plantarflexor specific torque in the elderly is associated with a lower activation capacity. Eur J Appl Physiol 2004;92:219-26.

[17] Muehlbauer T, Besemer C, Wehrle A, Gollhofer A, Granacher U. Relationship between strength, power and balance performance in seniors. Gerontology 2012;58:504-12.

[18] Muehlbauer T, Besemer C, Wehrle A, Gollhofer A, Granacher U. Relationship between strength, balance and mobility in children aged 7-10 years. Gait Posture 2013;37:108-12.

[19] Muehlbauer T, Gollhofer A, Granacher U. Association of balance, strength and power measures in young adults. J Strength Cond Res 2012.

[20] Munn J, Sullivan SJ, Schneiders AG. Evidence of sensorimotor deficits in functional ankle instability: a systematic review with metaanalysis. J Sci Med Sport 2010;13:2-12.

[21] Pizzigalli L, Filippini A, Ahmaidi S, Jullien H, Rainoldi A. Prevention of falling risk in elderly people: the relevance of muscular strength and symmetry of lower limbs in postural stability. J Strength Cond Res 2011;25:567-74.
[22] Pua YH, Liang Z, Ong PH, Bryant AL, Lo NN, Clark RA. Associations of knee extensor strength and standing balance with physical function in knee osteoarthritis. Arthritis care \& research 2011;63:1706-14.

[23] Sayers SP. High-speed power training: a novel approach to resistance training in older men and women. A brief review and pilot study. J Strength Cond Res 2007;21:518-26.

[24] Shaffer SW, Harrison AL. Aging of the somatosensory system: a translational perspective. Phys Ther 2007;87:193-207.

[25] Snowden M, Steinman L, Mochan K, Grodstein F, Prohaska TR, Thurman DJ, et al. Effect of exercise on cognitive performance in communitydwelling older adults: review of intervention trials and recommendations for public health practice and research. Journal of the American Geriatrics Society 2011;59:704-16.

[26] Sturnieks DL, St George R, Lord SR. Balance disorders in the elderly. Neurophysiol Clin 2008;38:467-78.

[27] Tseng CN, Gau BS, Lou MF. The effectiveness of exercise on improving cognitive function in older people: a systematic review. The journal of nursing research : JNR 2011;19:119-31.

[28] Watson AW. Sports injuries in footballers related to defects of posture and body mechanics. J Sports Med Phys Fitness 1995;35:289-94.

[29] Winter DA. Biomechanics and Motor Control of Human Movement. 3 ed: Wiley; 2004.

[30] Woollacott MH, Shumway-Cook A. Changes in posture control across the life span--a systems approach. Phys Ther 1990;70:799-807. 